\title{
BENEFITS OF AN ANIMAL TRACEABILITY SYSTEM FOR A FOOT-AND-MOUTH DISEASE OUTBREAK: A SUPPLY-DRIVEN SOCIAL ACCOUNTING MATRIX APPROACH
}

\author{
MAN-KEUN KIM* \\ Department of Applied Economics, Utah State University, Logan, Utah \\ C. MICHAEL UKKESTAD \\ Goldman Sachs, Salt Lake City, Utah \\ HERNAN A. TEJEDA \\ Department of Agricultural Economics and Rural Sociology, University of Idaho, Moscow, Idaho \\ DEEVON BAILEY \\ Department of Applied Economics, Utah State University, Logan, Utah
}

\begin{abstract}
This study reports the findings for an analysis using the computer program NAADSM (North American Animal Disease Spread Model) and a supply-driven social accounting matrix to examine the impact of a hypothetical foot-and-mouth disease (FMD) outbreak in a relatively isolated part of the United States, Utah, under various levels of livestock traceability. The analysis demonstrates that a significant regional economic impact in Utah would result from an FMD outbreak but that improved levels of traceability would be very important in helping to reduce the negative economic consequences of the outbreak.
\end{abstract}

Keywords. Animal traceability, foot-and-mouth disease, regional economic impact, supply-driven social accounting matrix

JEL Classifications. L15, Q13, Q18, R15

\section{Introduction}

Interest in livestock and meat traceability systems in the United States has waxed and waned during the past 15 years beginning in earnest with the first U.S.based case of bovine spongiform encephalopathy (BSE) in December 2003. The discovery of BSE in the United States led to a major effort starting in

This research was supported by the Utah Agricultural Experiment Station, Utah State University and approved as journal paper number 8799 . The authors appreciate the thoughtful comments of three anonymous reviewers.

*Corresponding author’s e-mail: mk.kim@usu.edu 
2005 by the U.S. Department of Agriculture (USDA), Animal and Plant Health Inspection Service (APHIS) to implement the National Animal Identification System (NAIS). ${ }^{1}$ NAIS was designed as a mandatory system that would have been used to track livestock (cattle, poultry, horses, donkeys, mules, sheep, goats, and swine) movements in the United States by establishing an identification number for premises where livestock were located, assigning animals an identification number (either individual or group), and implementing a national, electronic database for livestock tracking. The tracking component of NAIS would have required reporting and electronic filing for various different events in an animal's life, including changes in animal ownership or movement to a new premise (USDA, 2006). Additional events needing to be reported included applying ID tag, lost tags, replaced tags, death, slaughter, missing animals, and so forth.

NAIS had been supported by segments of the livestock industry (e.g., Green, 2010; Jordan, 2009; National Pork Production Council, 2009) and also had strong support from the animal health community (Bailey, 2007; Bailey and Slade, 2004; Lawrence, 2004), which viewed such a system as being an important component of tracking, controlling, and eradicating animal disease outbreaks. However, political pressure, especially from small livestock producers and the cattle industry concerning the issues of cost and confidentiality led the USDA in 2013 to dramatically cut back on its original goals related to animal tracking and traceability through NAIS (Greene, 2010; Morell, 2006; USDA-APHIS, 2013; Weston A. Price Foundation, 2013). Currently, only livestock moving across state lines must be documented in some fashion, ${ }^{2}$ and sheep, goats, and swine are not subject to these new requirements (USDA-APHIS, 2013).

Besides its potential value to track and eradicate animal disease, traceability systems have also been considered to be potentially important in facilitating trade and consumer acceptance of livestock and meat products (e.g., Dickinson and Bailey, 2002, 2005; Hobbs et al., 2005; Ward, Bailey, and Jensen, 2005). However, with the failure to implement NAIS, the U.S. traceability system continues to lag other major meat-exporting countries (Brester et al., 2011; Liddell and Bailey, 2001; Schroeder and Tonsor, 2012). For example, Brester et al. (2011) report that India and the United States are the only two major beef exporters that do not have mandatory traceability systems.

During the past decade, meat exports have become an increasingly important component of the U.S. meat complex (Klobuchar, 2013), for example, the USDA Economic Research Service (2014) reports that $10 \%$ of total U.S. beef production in 2013 was exported. This was up from $4.4 \%$ of production exported in 2006. Thus, any disruption in trade would have significant economic consequences for

1 The forerunner of NAIS was the U.S. Animal Identification Plan, which was announced in 2003. NAIS was announced in April 2004 (Lawrence, 2004).

2 This documentation may be certification by a veterinarian, owner-shipper statements, or brand certificates (Weston A. Price Foundation, 2013). 
the U.S. meat industry. If discovered, certain animal diseases, including BSE and communicable diseases such as foot-and-mouth disease (FMD), would pose a potential barrier to the export meat trade such as was experienced in the months following the first U.S. BSE case and as was experienced in connection to the United Kingdom's FMD outbreak in 2001 (Pendell et al., 2007). Such trade disruptions had large negative impacts on livestock producers, and the potential for future disruptions resulting from the discovery of various animal diseases should continue to be an important consideration for the livestock industry.

This article reports the findings of a study that used the social accounting matrix (SAM) framework to identify the impact of an FMD outbreak in a relatively isolated part of the United States (the state of Utah), considering various levels of livestock traceability. Utah is a moderately ranked livestock producer in the United States, ranking 23rd in dairy production, 33rd in cattle, 14th in swine, and 8th in sheep. However, livestock comprises a major portion of the agricultural economy of Utah. According to the USDA's 2012 Census of Agriculture (https://www.agcensus.usda.gov/Publications/2012/), livestock and livestock products make up $68 \%$ of the market value of all agricultural products sold (nearly $\$ 1.24$ billion). Results from the study provide a useful assessment of the effects of a potential FMD outbreak. States where livestock has a major role in the state's agricultural economy will benefit greatly from this study.

The input-output (IO) analysis using the IMPLAN (impact analysis for planning) database (MIG Inc.), more specifically the SAM approach, is utilized to measure the impact of an FMD outbreak and the benefits of animal traceability. Previous studies that have used the IO framework to examine the economic impact of FMD outbreaks are Garner and Lack (1995) for Australia, Ekboir (1999) for a hypothetical FMD outbreak in California, Mahul and Durand (2000) for France, Cozzens et al. (2010) for swine-transmitted FMD in Missouri, and Moon, Park, and Soh (2013) for Korea.

Pendell et al. (2007) analyze the hypothetical FMD impacts on the southwest Kansas economy using the SAM approach. Although prior studies (Cozzens et al., 2010; Ekboir, 1999; Garner and Lack, 1995; Mahul and Durand, 2000; Moon, Park, and Soh, 2013; Pendell et al., 2007, 2015; Schroeder et al., 2015) have used a similar analysis to estimate the economic impact of an FMD outbreak at different levels of the marketing chain, this study specifically imposes different levels of traceability and uses a novel supply-driven SAM (SDSAM) model (explained subsequently) based on the IMPLAN database to estimate the economic benefit of better traceability. Note that Kim (2015) investigates the actual 2010-2011 FMD impacts on the Korean economy using the supply-driven IO model. This study expands the supply-driven IO framework in Kim (2015) to the SDSAM, assesses the economic impacts of a hypothetical FMD outbreak in a U.S. region where livestock has a considerably prominent role in its (agricultural) economy despite its small national volume, and attempts to calculate the benefit of livestock traceability. 
Some previous studies (e.g., Fernández-Macho, Gallastegui, and González, 2008; Leung and Pooley, 2001; Seung and Waters, 2009) have argued that it is more appropriate to use a supply-driven IO model than a (final) demanddriven IO model in situations where the output level is altered directly from a shock such as an FMD outbreak. That is, in a supply-driven IO model, a "supply reduction" may occur and be characterized as the "shock" the system experiences, rather than having a shock resulting from a shift in the demand curve. This is important for a case such as an FMD outbreak because the supply effects are much clear than the immediate demand effects as the change in (final) demand is unknown. ${ }^{3}$ Using supply-driven IO multipliers, we calculate both the backward and forward linkage effects of an FMD outbreak in Utah. Following this calculation, the analysis demonstrates that a substantial economic impact would result from such an outbreak. More importantly, however, improved levels of traceability would significantly reduce the negative economic consequences of the outbreak. Thus, the novelty of this article is in identifying whether livestock traceability can substantially reduce economic loss from FMD even in a midtiered livestock-producing state. Note that we confine our study to the state of Utah to investigate FMD impact. We acknowledge that FMD may spread to neighboring states across Utah borders; however, this is beyond the scope of this study and the matter of another study.

Section 2 provides an overview of FMD and the economic impact from studies that provided the basis for this analysis, and Section 3 introduces the epidemiological simulation model, the computer program NAADSM (North American Animal Disease Spread Model). Section 4 presents a formal discussion of the supply-driven IO and SAM models, and Section 5 discusses results and implications.

\section{FMD Outbreaks and Their Economic Impact}

FMD is a highly contagious viral disease that affects cloven-hoofed animals such as cattle, swine, sheep, and goats. The disease can be transmitted directly through animal movement or indirectly through nonanimal fomites or airborne transmission. ${ }^{4}$ Typically, fewer than $6 \%$ of infected, adult animals are actually killed by the disease (Mahul and Gohin, 1999), whereas mortality is about $80 \%$ in young animals (Rich, Miller, and Winter-Nelson, 2005). Despite the low mortality and nonzoonotic nature of FMD, an outbreak

3 There would be a final demand shock because of an FMD outbreak, but it would not be significant. Very few final end consumers buy live cattle (final demand accounts for only $0.4 \%$ of total production). Packers' demand is not considered as the final demand in the SAM model given that it is the intermediate input for the industry.

4 Fomite is any element capable of carrying infectious bacteria and viruses such as contaminated facilities, transportation, clothing, air, and animal products that may be indirect routes of transmission of FMD. 
results in animal debilitation and substantial losses in both milk and meat production. Because it is highly infectious and spreads quickly, culling (killing or depopulating) exposed animals is inevitable, resulting in substantial economic losses.

The impact of a potential FMD outbreak on the international market has grown to be a major concern for livestock exporters as food supply chains have become increasingly globalized (Park, Jin, and Bessler, 2008). Pendell et al. (2007) emphasize that management strategies and the emergency response to an FMD outbreak greatly influence its expected economic impact. For example, Pendell et al. $(2007$, p. 21) state that "if FMD is discovered, aggressive quarantines, substantial restrictions on animal movement, and stamping-out of exposed animals are strategies enacted to attempt to rapidly arrest and eradicate the disease ... vaccination strategies may [also] be employed."

The United Kingdom experienced a severe FMD outbreak in 2001 following 34 years of being FMD free. At least 57 premises were infected by the time the first case was identified in February 2001 (Scudamore, 2002). By September 2001, more than 6 million animals were depopulated, and the disease spread to Ireland, France, and the Netherlands (Scudamore, 2002). Thompson et al. (2002) estimate FMD losses in the United Kingdom at US\$5 billion. As Pendell et al. (2007) point out, the UK FMD outbreak demonstrates the need to understand the economic impacts of FMD when developing effective public policies. Paarlberg et al. (2008) investigate a hypothetical outbreak of FMD in the United States and show that there would be large trade-related losses for livestock though few animals would be destroyed. Paarlberg et al. (2008) estimate that the total losses attributable to FMD range between $\$ 2.8$ billion and $\$ 4.1$ billion depending on disease intensity, duration, and the response scenario.

In Korea, FMD outbreaks occurred in 2000, 2002, and 2010 (Korea Rural Economic Institute [KREI], 2011). The Korean FMD outbreaks in 2000 and 2002 were not severe, and the number of animals depopulated was 2,216 head in 2000 and 160,155 head in 2002 (KREI, 2011). The 2010-2011 Korean FMD outbreak, however, was much more severe and caused large economic losses in the livestock sectors when up to 3.5 million head of animals (mostly swine) were culled. KREI (2011) estimates the direct supply reduction (percent of the total value of production) in the swine sector in Korea during the 2010-2011 outbreak was $32 \%$, whereas the direct supply reductions in the dairy and beef cattle sectors were only $8.4 \%$ and $3.9 \%$, respectively (KREI, 2011, p. 283). Moon, Park, and Soh (2013) estimate the total economic impact of the 2010-2011 FMD outbreak in Korea to be about US\$3.2 billion using the (demand-driven) IO model. Kim (2015) provides a much larger loss of $\$ 6.8$ billion using the supply-driven IO framework. Given the fact that FMD can inflict such large and unexpected losses to a region and/or country's economy, there are significant economic incentives to design public policies that could aid in mitigating or limiting the effects of FMD outbreaks. 
Schroeder et al. (2015) also investigate economic impacts of a hypothetical FMD outbreak in the midwestern United States This research, however, focuses on the benefit of alternative FMD emergency vaccination strategies, which may reduce disease spread duration. As a result, not having a high-capacity vaccination program would reduce consumer and producer surplus to $\$ 56$ billion from $\$ 188$ billion (i.e., the latter having vaccination strategies). Pendell et al. (2015) examine the economic impact of hypothetical (unintentional) FMD releases from the (future) National Bio and Agro Defense Facility in Manhattan, Kansas. The release events modeled include aerosol, liquid waste, transference (unannounced release events), and a tornado (announced release event). Total damages for the FMD release events range from about $\$ 16$ billion to $\$ 140$ billion (sum of consumer and producer surplus).

\section{Epidemiological Modeling—NAADSM}

\subsection{Overview}

Epidemiological modeling is a vital tool in the analysis of potential disease outbreaks under alternate control strategies. This case presents the potential benefits associated with various levels of traceability during an FMD outbreak. The use of an epidemiological model to simulate disease outbreaks is particularly beneficial in regions or countries where FMD is not present and therefore cannot be studied through direct observation (Mardones et al., 2010). This research utilizes the NAADSM, which is a stochastic, spatial, and state-transition simulation model that can estimate the direct impact (number of depopulated animals) across alternative traceability levels occurring during an FMD outbreak.

The NAADSM was developed under the guidance of USDA-APHIS. It is a flexible tool that can simulate the temporal and spatial spread of FMD at the herd level (Harvey et al., 2007). The NAADSM has been used by Pendell (2006), Pendell et al. (2007), Paarlberg et al. (2008), Cozzens et al. (2010), Jones (2010), McReynolds (2013), Schroeder et al. (2015), and Pendell et al. (2015) to simulate outbreaks of FMD in selected regions of the United States and Canada, as well as to analyze the efficacy of various control strategies.

Formal discussion regarding the NAADSM is minimal here because the main research question is to estimate the benefit of different traceability levels as estimated by the supply-driven regional economic impacts resulting from a hypothetical FMD outbreak. Please refer to Ukkestad (2014) for a comprehensive discussions regarding the NAADSM as it was applied to the situation in Utah. The key input parameters in the NAADSM are animal population including production type and the location of each herd, disease manifestation, disease transmission, disease detection and surveillance, disease control, and direct costs (Reeves et al., 2012). 
The production types included in the simulations are cow-calf, large feedlots $(>3,000)$, small feedlots $(<3,000)$, dairy, large swine $(>1,000)$, small swine $(<1,000)$, and sheep operations. The size data for each production type were compiled from the USDA National Agricultural Statistics Service's (NASS) 2012 Census of Agriculture. Because of privacy issues, the exact locations of the operations are unavailable. This article adapted the technique in Jones (2010). From the Census of Agriculture, the number of herds for each type of operation is known for each county. Using the geographic information systems package ArcGis ${ }^{\circledR}$, a boundary file containing county distinctions was placed over a map of Utah. Using a random point generator contained in the software package, a number of random points equal to the number of operations were generated within the borders of each county.

The inputs for disease manifestation concern the characteristics of each production type and are divided into four disease states: latent, subclinically infectious, clinically infectious, and immune. These are represented by probability distribution functions for the duration of each disease state for a herd of each production type. Parameters for probability distribution functions for latent, subclinical, and clinical states are adopted from Mardones et al. (2010) for cowcalf, feedlot, dairy, and swine, and from Premashthira et al. (2011) for sheep. The probability distribution functions for the duration of the immune state for cowcalf, feedlot, dairy, and swine operations are taken from empirical distributions used in Pendell (2006).

\subsection{Disease Detection and Traceability}

As defined within the NAADSM, disease detection refers to the likelihood that farmers and ranchers will observe and report an FMD outbreak in their herds. The NAADSM uses the probability (density) of observing clinical signs of an infected herd and the likelihood that an infected herd will be reported as time passes. The NAADSM allows for outside surveillance parameters to be specified that could affect this process. The relevant parameters for the purpose of this research concern "trace-out," or more commonly traceability.

Following Pendell (2006) and Jones (2010), three different probabilities (30\%, $60 \%$, and $90 \%$ ) are used to reflect three different levels or depths of traceability: low, medium, and high levels of traceability. A 30\% probability of a successful trace-out is a level of success we believe adequately reflects the present level of trace-out intensity in the United States (Pendell, 2006). According to Reeves et al. (2012, p. 111), “Tracing refers to the process of identifying units (herds) at high risk for disease based on contact with detected units ... Tracing-out is the process of determining which units received a contact from ... infected by ... Tracing-back is ... which units were sources of contact and potential sources ... In NAADSM, units identified by tracing will be automatically quarantined and thus can no longer spread disease by indirect contact." Note that the NAADSM conducts only one level of trace-out (Hill and Reeves, 2006, p. A-16 [appendix]). 
Table 1. Foot-and-Mouth Disease (FMD) Outbreak and Average Number of Animals Depopulated (head) (1,000 iterations)

\begin{tabular}{llll}
\hline \hline & $\begin{array}{l}\text { Low }(30 \%) \\
\text { Traceability }\end{array}$ & $\begin{array}{l}\text { Medium (60\%) } \\
\text { Traceability }\end{array}$ & $\begin{array}{l}\text { High }(90 \%) \\
\text { Traceability }\end{array}$ \\
\hline Outbreak duration (days) & 160 & 154 & 150 \\
Standard deviation (days) & 63 & 59 & 55 \\
Fed cattle depopulated & 8,730 & 7,480 & 6,611 \\
Feeder cattle depopulated & 17,702 & 11,132 & 8,029 \\
Dairy cows depopulated & 21,315 & 18,324 & 17,231 \\
Swine depopulated & 100,059 & 89,564 & 88,433 \\
Sheep depopulated & 15,148 & 14,303 & 13,273 \\
\hline Total animals depopulated & 162,954 & 140,803 & 133,577 \\
Standard deviation (head) & 92,987 & 103,843 & 96,507 \\
\hline \hline
\end{tabular}

Notes: Numbers are average of 1,000 iterations other than indicated. We draw a set of 1,000 simulations from various distribution assumptions of model parameters to invoke normality but not tested formally.

In the scenario involving a low level of trace success, the simulated outbreak results in a $37 \%$ decrease in Utah's fed cattle population. This percentage is reduced to $31 \%$ under the medium level of trace success and $28 \%$ under the highest level. The large size of these mean effects is the result of 3 of Utah's 132 feedlot operations possessing nearly half of the state's fed cattle population so that once FMD is detected in the NAADSM (North American Animal Disease Spread Model) simulation, the depopulation of any of these 3 feedlot operations has a disproportionate effect on the overall fed cattle population.

The number of feeder cattle depopulated under the 30\%,60\%, and $90 \%$ trace success scenarios are $5 \%, 3 \%$, and $2 \%$, respectively. Similarly to feedlots in Utah, a small number of swine operations in Utah contain a disproportionate number of slaughter hogs, which resulted in larger relative depopulation in comparison with Pendell et al. (2006). Under the lowest level of trace success, $14 \%$ of slaughter hogs are depopulated. Under the medium and high trace success scenarios, $12.24 \%$ and $12.09 \%$ of slaughter hogs are depopulated, respectively.

Traceability can be simulated by setting the tracing parameter (the probability of trace success). The number of days before detection occurs after an animal came into direct or indirect contact with an infected herd is also specifiable in the NAADSM. A trace delay, or the delay in carrying out a trace investigation, can also be specified to reflect possible lags that may exist in the real world (for more details, see Ukkestad 2014). A 60\% probability reflects an adopted traceability system that might not yet be implemented for full traceability. A $90 \%$ success rate would reflect a nationally adopted, agile, and accurate system of traceability.

\subsection{NAADSM Results}

There are two primary metrics used for reporting the output of the epidemiological model for each scenario: the duration of the FMD outbreak and the summary statistics for the number of livestock depopulated during the outbreak. Overall, an inverse relationship was found to exist between the number of animals depopulated across all species and the probability of a successful traceability. The FMD duration and the number of animals depopulated by 
species are presented in Table 1 with 1,000 iterations performed for low, medium, and high levels of trace intensity.

In the scenario involving a low-level of traceability success $30 \%$ or the current state of animal identification), the hypothetical FMD outbreak results in a $36.6 \%$ decrease in Utah's fed cattle population, or 8,730 head. This percentage is reduced to $31.4 \%(7,480$ head $)$ under the medium level of traceability success $(60 \%)$ and $27.7 \%(6,611$ head $)$ under the highest traceability level $(90 \%)$. Thus, there is an approximately $24.3 \%$ reduction in the number of fed cattle depopulated when shifting from a low-level of traceability to the highest level of traceability. Moreover, the large percentages of fed cattle depopulated is likely a result of the fact that only 3 of Utah's 132 feedlot operations account for almost half of the state's entire fed cattle population.

As said, livestock comprises a major portion of the state agricultural economy of Utah. According to the USDA's 2012 Census of Agriculture, livestock and livestock products make up $68 \%$ of the market value of all agricultural products sold (nearly $\$ 1.24$ billion). Beef and dairy production make up the largest portion of livestock sales (about 30\% and 26\%, respectively). Swine consist of $23 \%$ of total agricultural sales. Although livestock production is a significant part of the state economy, Utah is a moderately ranked producer on a national scale, ranking $23 \mathrm{rd}$ in dairy production, $33 \mathrm{rd}$ in cattle, 14 th in swine, and 8 th in sheep. The total number of cattle on feed (for market) in Utah is about 24,000 head, and for feeder cattle, 365,000 head (number during 2012-2013). Consequently, once FMD is detected in the NAADSM simulation for Utah, the depopulation of any of these three feedlot operations has a disproportionate effect on the overall fed cattle population as a whole.

The number of feeder cattle depopulated under the $30 \%, 60 \%$, and $90 \%$ trace success scenarios is $4.8 \%$ (17,702 head), $3.0 \%$ (11,132 head), and $2.2 \%$ $(8,029$ head), respectively. There is a substantial $55 \%$ reduction in the number of feeder cattle depopulated when shifting from a low level of traceability to the highest level of traceability. In addition, when moving from a low level of traceability to a medium level of traceability, there still is an approximate $37 \%$ reduction of feeder cattle depopulation. So the improvements in this latter case, but even more so for the initial case of depopulated feeder cattle, are considerable.

In a similar way to Utah's feedlot industry, a small number of swine operations in Utah account for a disproportionate number of all swine in the state. This resulted in relatively large depopulation of the swine herd on a percentage basis compared with Pendell (2006). Under the lowest level of trace success, $13.7 \%$ $(100,059$ head) out of about 730,000 pigs in the state are depopulated. Under the medium and high trace success scenarios, $12.2 \%(89,564$ head) and $12.1 \%$ $(88,434$ head) of pigs are depopulated, respectively. Thus, in this case, there is approximately a $12 \%$ reduction in depopulation when shifting from a low level of traceability to a high level of traceability. 
This reflects that high levels of traceability significantly benefit the livestock system by limiting the spread of FMD across species in two different cases. The first case occurs for livestock in concentrated feeding situations (e.g., hogs and fed cattle), where they are disproportionately affected in regard to their total count. The other case occurs for livestock in nonconcentrated feeding situations, where there is a sizable percentage decrease in the number of species depopulated when shifting from a low level of traceability to a high level of traceability (e.g., feeder cattle). Because sheep in Utah tend to be concentrated in range operations with large herds, sheep are similarly disproportionately affected by an FMD outbreak as the first mentioned case (Table 1).

Note that the $30 \%, 60 \%$, and $90 \%$ trace success applies for all livestock considered in this study even though currently swine and dairy have higher degrees of traceability. Major dairy industries have pledged an $80 \%$ traceability as of 2015 (Lind, 2014).

\section{Measuring the FMD Impact Using an SDSAM}

The IO model or the SAM model used in this analysis is drawn up for the cattle ranching and farming and cattle and hog slaughter sectors ${ }^{5}$ in Utah using current conditions in these sectors as the starting point for the analysis. The SDSAM then evaluates the regional economic impacts of the hypothetical FMD outbreak in Utah based on the findings reported by the NAADSM for different levels of traceability.

Regional economic impact is defined as "the net changes in new economic activity associated with an industry, event, or policy in an existing regional economy" (Watson et al., 2007, p. 142). The event in this article is a hypothetical FMD outbreak in Utah, and thus "regional" means the Utah economy. We make the assumption in this case that FMD would not spread to other states and regions. Although this most likely may not be the case in an actual FMD outbreak, it establishes a baseline for the positive impact that traceability can have during an animal disease outbreak. Although an analysis of broader areas would exhibit larger impacts both for FMD and the ability of traceability to limit the impact of FMD, the results in either case are expected to reflect the central conclusion that traceability would be a very useful tool in limiting the effects of an FMD outbreak. The economic impact estimated in the article is solely for Utah. Note, however, that when FMD occurs in Utah, livestock and their meat exports would be banned nationwide, which is not included as the impact in this study.

Developed by Leontief (1941), the IO model is constructed from a detailed set of industry accounts that measure the commodities produced by each industry

5 The terminology and spelling for cattle ranching and farming and cattle and hog slaughter sectors correspond with sectors identified in the IMPLAN model. 
and the use of these commodities by other industries and (exogenous) final users. By incorporating information about interindustry relationships or direct requirements, IO multipliers can track the impact of the (exogenous) final demand changes on particular industry sectors within a region. Although IO models are useful for examining the relationship between industries and valueadded activities, they cannot examine the distributional impacts such as effects on households or state and local government. The SAM approach can measure these latter impacts (Polo and Valle, 2012), and IMPLAN (MIG Inc.) is the commercialized data and software model typically used to provide these kinds of analyses, including for this study. As argued in the introduction and literature review, the supply-driven multipliers are used in this analysis to calculate both backward and forward linkage effects of an FMD outbreak in Utah.

\subsection{Supply-Driven IO and SAM Multipliers}

The IO model is represented by $x=A x+y$ for an economy of $n$ sectors (industries), where $x$ is the output vector, $y$ is the final demand vector (household consumption, government expenditure, and export), and $A$ is the direct requirement (or technical coefficients) matrix. Elements in the matrix $A, a_{i j}$, are calculated as $a_{i j}=x_{i j} / x_{j}$, where $x_{i j}$ is the value of transactions between sector $i$ and $j$, and $x_{j}$ is the sectoral output which is $x_{j}=\sum_{i}^{n} x_{i j}$. This relation indicates that the sum of output $x$ equals its direct uses in final demand $y$ and its indirect uses in intermediate production, $A x$. The solution of $x=A x+y$ can be obtained by rewriting it as $x=(I-A)^{-1} y$, where $I$ is an $n \times n$ identity matrix. Intuitively, this can be interpreted as $\Delta x=(I-A)^{-1} \Delta y$, which means that changes in total industry output because of changes in final demand are predicted using $(I-A)^{-1}$. The column sum of $(I-A)^{-1}$ is interpreted as the total changes in output from the changes in final demand or the output multiplier.

As argued, however, (output) multipliers based on the final demand approach do not completely reflect all the economic impacts from an FMD outbreak, which is considered as a direct supply reduction. Leung and Pooley (2001), FernándezMacho, Gallastegui, and González (2008), and Seung and Waters (2009) have suggested that it is more appropriate to use a supply-driven model in situations where the output level is directly altered, not final demand. Following Leung and Pooley (2001), the IO model, $x=A x+y$, can be partitioned as follows:

$$
\left[\begin{array}{l}
x_{1} \\
x_{2}
\end{array}\right]=\left[\begin{array}{ll}
A_{11} & A_{12} \\
A_{21} & A_{22}
\end{array}\right]\left[\begin{array}{l}
x_{1} \\
x_{2}
\end{array}\right]+\left[\begin{array}{l}
y_{1} \\
y_{2}
\end{array}\right]
$$

where a subscript " 1 " indicates the exogenized sectors in which supply reduction occurs (e.g., cattle ranching and farming and cattle and hog slaughter sectors), and " 2 " indicates the other endogenous sectors. Thus, $x_{1}$ is a vector of outputs 
of the exogenized sectors, $x_{2}$ is a vector of outputs of the endogenous sectors, $y_{1}$ is a vector of the final demand of the corresponding exogenized sectors, and $y_{2}$ is a vector of the final demands of the corresponding endogenous sectors.

Correspondently, the direct requirement matrix $A$ is partitioned into four submatrices as in equation (1). We obtain equation (2) by solving equation (1) for $x_{2}$ (endogenous sectors) assuming $\Delta y_{2}$ is zero:

$$
x_{2}=\left(I-A_{22}\right)^{-1} A_{21} x_{1} \text {, or } \Delta x_{2}=\left(I-A_{22}\right)^{-1} A_{21} \Delta x_{1},
$$

where $\left(I-A_{22}\right)^{-1} A_{21}$ is the backward linkage (Leung and Pooley, 2001). The backward linkage is "a sector's relationship to upstream sectors (suppliers) that provide goods and services used as intermediate inputs" (Seung and Waters, 2009 , p. 19). This measures the change in output in endogenous sectors because of change in the output of the exogenized sectors. In the case of an FMD outbreak, the reduction in output in the cattle ranching and farming sector may reduce the sector's demand for inputs purchased from other sectors such as labor (employment compensation), feed, manufactured items (agricultural machinery), financial supports (banking service, insurance), legal services, and so on.

Following Leung and Pooley (2001) again, a similar framework can be extended to the forward linkage effects using the Ghosh model (Ghosh, 1958). The Ghosh model can be expressed as $x \prime=x / B+v$, where $B$ represents the output distribution pattern of each sector as opposed to $A$ (i.e., the forward linkage; the column sum of IO table). It is the allocation of a sector's output to the other sectors including value added, $v$ (Leung and Pooley, 2001). The usual analysis looks at the effect of a change in final factor input or value added $(v)$ on sectoral outputs; that is, $x \prime=v(I-B)^{-1}$. Using a similar partition, the Ghosh model can be rewritten as follows:

$$
\left[\begin{array}{ll}
x_{1}^{\prime} & x_{2}^{\prime}
\end{array}\right]=\left[\begin{array}{ll}
x_{1}^{\prime} & x_{2}^{\prime}
\end{array}\right]\left[\begin{array}{ll}
B_{11} & B_{12} \\
B_{21} & B_{22}
\end{array}\right]+\left[\begin{array}{ll}
v_{1} & v_{2}
\end{array}\right],
$$

where $v_{1}$ is a vector of value added of the exogenized sectors and $\mathrm{v}_{2}$ is a vector of value added of the endogenous sectors. Again, assuming $\Delta v_{2}=0$,

$$
x_{2}^{\prime}=x_{1}^{\prime} B_{12}\left(I-B_{22}\right)^{-1}, \text { or } \Delta x_{2}^{\prime}=\Delta x_{1}^{\prime} B_{12}\left(I-B_{22}\right)^{-1},
$$

where the row sum of the matrix $B_{12}\left(I-B_{22}\right)^{-1}$ in equation (4) can be considered as the forward linkage multipliers. Seung and Waters (2009, pp. 19-20) define the forward linkages as "a sector's relationship with its downstream demanders who purchase goods and services from the exogenized sectors." In the case of FMD outbreaks, reductions in output in the cattle ranching and farming sector may reduce the output of meat processing (manufacturing sector) and wholesale sectors that purchase inputs from the cattle ranching and farming sector. Note that, based on the NAADSM analysis, most of the loss from an FMD outbreak would occur in the cattle and hog slaughter sector and would be considered as a direct impact rather than an indirect impact in this analysis. 
Fernández-Macho, Gallastegui, and González (2008) and Seung and Waters (2009) extend the supply-driven IO approach to the SDSAM approach. Following the notations in Holland and Wyeth (1993) and discussions in Seung and Waters (2009), the matrix of direct requirement in the SDSAM, denoted $S$, instead of the matrix $A$ in the IO model, is given by

$$
S=\left[\begin{array}{ccccc}
A & 0 & 0 & C & G D \\
V & 0 & 0 & 0 & 0 \\
I B T & 0 & 0 & 0 & 0 \\
0 & F & 0 & I H T & S T R \\
0 & S F & B T S & H T X & I G T
\end{array}\right],
$$

where $A$ is the matrix of direct requirement from the IO model, $V$ is the matrix of primary factor payments (i.e., employment compensation, proprietor income and other property income, coefficients), IBT is the matrix of indirect business tax coefficients, $F$ is the matrix of factor payments or value-added distributions to the households, $S F$ is the matrix of state and local factor tax coefficients, $B T S$ is the matrix of state and local indirect business tax coefficients, $C$ is the matrix of household consumption, IHT is the matrix of interhousehold transfer coefficients, HTX is the matrix of state and local government direct household tax coefficients, GD is the matrix of state and local government demand coefficients, STR is the matrix of state and local government transfer coefficients, and IGT is the matrix of intergovernmental transfers. Similar to the final demand-driven IO, the final demand-driven SAM is represented as

$$
\left[\begin{array}{c}
q \\
v \\
i b t \\
b \\
s g
\end{array}\right]=(I-S)^{-1}\left[\begin{array}{c}
e q \\
e v \\
e t \\
e b \\
e g
\end{array}\right]
$$

where $q$ is the vector of outputs of the endogenous sectors; $v$ is the vector of primary factor payments, which is also endogenous; $i b t$ is the indirect business tax payments; $h$ is the vector of household income; and $s g$ is the vector of state and local government income or revenue. The vectors $e q, e v, e t, e h$, and eg are exogenous demand (export), exogenous factor payments, exogenous indirect business tax payments, exogenous federal transfers to household, and federal transfers to state and local government, respectively. The parameter $(I-S)^{-1}$ is the SAM multiplier matrix.

To convert the SAM model to the SDSAM, the output vector and the SAM matrix $S$ are partitioned as in equation (1) such that

$$
\left[\begin{array}{l}
x_{1} \\
x_{2}
\end{array}\right]=\left[\begin{array}{ll}
S_{11} & S_{12} \\
S_{21} & S_{22}
\end{array}\right]\left[\begin{array}{l}
x_{1} \\
x_{2}
\end{array}\right]+\left[\begin{array}{l}
e x_{1} \\
e x_{2}
\end{array}\right]
$$


where $x_{1}=q_{1}$ is the vector of outputs of the exogenized sectors, $x_{2}=$ $\left[q_{2}^{\prime}, v^{\prime}, i b t^{\prime}, h^{\prime}, s g^{\prime}\right]^{\prime}, e x_{1}=e q_{1}$, and $e x_{2}=\left[e q_{2}^{\prime}, e v^{\prime}, e t^{\prime}, e h^{\prime}, e g^{\prime}\right]^{\prime}$. Again, solving the linear equations system in equation (7) for $x_{2}$ assuming $\Delta e x_{2}=0$ gives

$$
x_{2}=\left(I-S_{22}\right)^{-1} S_{21} x_{1} \text {, or } \Delta x_{2}=\left(I-S_{22}\right)^{-1} S_{21} \Delta x_{1} .
$$

Here, the column sum of $\left(I-S_{22}\right)^{-1} S_{21}$ is the backward linkage SDSAM multiplier (Seung and Waters, 2009).

Similarly, the Ghosh model of the SAM can be represented as

$$
\left[\begin{array}{ll}
x_{1}^{\prime} & x_{2}^{\prime}
\end{array}\right]=\left[\begin{array}{ll}
x_{1}^{\prime} & x_{2}^{\prime}
\end{array}\right]\left[\begin{array}{ll}
R_{11} & R_{12} \\
R_{21} & R_{22}
\end{array}\right]+\left[\begin{array}{ll}
e v_{1} & e v_{2}
\end{array}\right],
$$

where $R$ is a direct output coefficient matrix as opposed to the matrix $S$. The matrix $R$ shows how the output of industries is distributed across purchasing industries as in the matrix $B$ in equation (3). $R_{i j}$ is the partitioned matrix of $R$; $e v_{1}$ and $e v_{2}$ are vectors of exogenous value-added terms such as imports or income leakages from industries. Again, solving the system in equation (9) for $x_{2}$ assuming $\Delta e v_{2}=0$ gives

$$
x_{2}^{\prime}=x_{1}^{\prime} R_{12}\left(I-R_{22}\right)^{-1} \text {, or } \Delta x_{2}=\Delta x_{1}^{\prime} R_{12}\left(I-R_{22}\right)^{-1},
$$

and the row sum of $R_{12}\left(I-R_{22}\right)^{-1}$ is the forward linkage SDSAM multiplier (Seung and Waters, 2009).

\subsection{Direct FMD Impact from NAADSM}

As seen in Table 1, the cumulative expected number of animals depopulated differs according to the traceability scenario. The value of the direct impacts for the cattle ranching and farming sector and the hogs and sheep sectors (other livestock sectors) are computed using simulated results in Table 1 . The direct impacts for both cattle ranching and farming and other livestock sectors are calculated as the number of animals depopulated $\times$ average (regional) value of animals per head from Utah Agricultural Statistics and Utah Department of Agriculture and Food 2015 Annual Report (USDA-NASS, Utah Field Office, 2015) (Table 2). The direct impact on the cattle and hog slaughter sector is calculated as

Value of animals per head $\times$ number of animals depopulated from NAADSM.

That is to say, the cattle and hog slaughter sector in Utah is assumed to experience the same percentage reduction as indicated by the NAADSM. Note that most of the hogs produced in Utah are not slaughtered in Utah, and thus no direct impact is found (Table 2).

\subsection{Utab SAM and Supply-Driven Impacts}

The Utah regional economy is constructed into 16 aggregated sectors using the IMPLAN database for the year 2010 (MIG Inc.). Although most of these sectors 
Table 2. Estimated Direct Impact of a Foot-and-Mouth Disease Outbreak (millions of dollars)

\begin{tabular}{|c|c|c|c|c|}
\hline IMPLAN Sector & & Low & Medium & High \\
\hline \multirow[t]{4}{*}{ Cattle ranching and farming ${ }^{\mathrm{a}}$} & Fed cattle depopulated & -10.854 & -9.300 & -8.220 \\
\hline & Feeder cattle depopulated & -22.009 & -13.841 & -9.983 \\
\hline & Dairy cows depopulated & -30.765 & -26.448 & -24.870 \\
\hline & Subtotal & -63.628 & -49.589 & -43.072 \\
\hline \multirow[t]{3}{*}{ Other livestock } & Swine depopulated & -13.841 & -12.390 & -12.233 \\
\hline & Sheep depopulated & -3.363 & -3.175 & -2.947 \\
\hline & $\underline{\text { Subtotal }}$ & -17.204 & -15.565 & -15.180 \\
\hline Cattle and hog slaughter & $\begin{array}{l}\text { Beef slaughtering } \\
\text { Hog slaughtering }\end{array}$ & -62.890 & -52.042 & -44.850 \\
\hline Total direct impact & & -143.723 & -117.195 & -103.103 \\
\hline
\end{tabular}

${ }^{a}$ Direct impact $=$ value of animals per head $\times$ number of animals depopulated. Values of animals per head are the average of 2012, 2013, and 2014 and are compiled from Utah Agricultural Statistics and Utah Department of Agriculture and Food 2015 Annual Report (USDA-NASS, Utah Field Office, 2015). Value of fed and feeder cattle is assumed to be $\$ 1,243$ per head; dairy cows, $\$ 1,443$ per head; swine, $\$ 138$ per head; and sheep, $\$ 222$ per head, respectively.

${ }^{\mathrm{b}}$ Most of hogs produced in Utah are not slaughtered in Utah, and no direct impact is assumed.

are highly aggregated, those sectors directly affected by the FMD outbreaks (e.g., cattle ranching and farming, other livestock, and cattle and hog slaughter) are broken out into further detail. As seen in Table 3, the gross regional product (sum of total value added) was $\$ 109$ billion in Utah in 2010, and this level of economic activity supported an estimated 1.6 million jobs (Table 3). Major sectors include manufacturing, FIRE (finance, information, real estate, and education), other services, and government, which were estimated to support about 1.1 million jobs in Utah. In 2010, the cattle ranching and farming sector produced an output of $\$ 583$ million and supported an estimated 4,848 jobs in Utah. The cattle and hog slaughter sector generated an output of $\$ 1,067$ million in 2010 and supported 2,391 jobs.

The regional impacts based on various outbreak scenarios are computed using the backward and forward SDSAM multipliers based on the direct impacts of FMD outbreaks reported in Table 2 and are presented in Tables 4, 5, and 6. In the case of a low level of traceability (Table 4), the total regional impact (direct + indirect + induced) of an FMD outbreak is estimated to be $\$ 468$ million, and the multiplier (= total/direct) is calculated to be rather large at $3.26 .^{6}$ The total indirect impacts on industries are estimated to be $\$ 137$ million. Value

6 Direct effects are changes in the industries because of FMD (i.e., value of animals $\times$ number of animals depopulated); indirect effects are changes in other industries from interindustry relationships; induced effects reflect changes in spending from households and governments because of changes in income and tax revenue from FMD. Note that if we use the final demand-driven approach, the total regional economic impact is estimated to be $\$ 236$ million, which is much lower than the supply-driven result. 
Table 3. Aggregated Sectors in Utah (model year 2010)

\begin{tabular}{lrcr}
\hline \hline Sectors & $\begin{array}{c}\text { Output }\left(10^{6}\right. \\
\text { dollars })\end{array}$ & $\begin{array}{c}\text { Employment } \\
\left(10^{3} \text { persons }\right)\end{array}$ & $\begin{array}{c}\text { Total Value-Added } \\
\left(10^{6} \text { dollars }\right)\end{array}$ \\
\hline Other ag, forestry, fish, and hunting & 862 & 7.70 & 334 \\
Grain farming & 37 & 0.79 & 7 \\
Cattle ranching and farming & 583 & 4.85 & 157 \\
Other livestock & 392 & 7.47 & 151 \\
Mining & 4,099 & 14.31 & 2,622 \\
Utilities & 2,631 & 4.41 & 1,831 \\
Construction & 11,804 & 91.67 & 5,201 \\
Manufacturing & 50,457 & 111.83 & 13,596 \\
Cattle and hog slaughter & 1,067 & 2.39 & 122 \\
Wholesale trade & 6,823 & 48.90 & 5312 \\
Retail & 10,936 & 171.87 & 7,166 \\
Transportation and warehousing & 6,688 & 50.45 & 3,756 \\
FIRE & 46,299 & 291.16 & 27,472 \\
Other services & 42,380 & 567.83 & 25,227 \\
Government & 17,899 & 241.87 & 16,217 \\
\hline Total & 202,955 & $1,617.51$ & 109,171 \\
\hline \hline
\end{tabular}

${ }^{a}$ Finance, insurance, real estate, and education

added (employer compensation, proprietary income, other property income, and indirect business taxes) was estimated to decrease by $\$ 97$ million. As shown in Table 4, the household sectors were partitioned into three categories according to their income level (low, medium, and high) for brevity of presentation. Total household income is estimated to be reduced by $\$ 68$ million under (this) lowtraceability scenario, with more than half of this impact affecting households in the medium-income category. State and local government revenue is estimated to fall by $\$ 23$ million because of reduced taxes paid by industries and households.

In the case of a medium level of traceability (Table 5), the total regional loss resulting from an FMD outbreak in Utah is estimated to be $\$ 383$ million (18\% less than the loss estimated for the low level of traceability case). ${ }^{7}$ The gain from the implementation of a medium level of traceability over a low level of traceability during an FMD outbreak in Utah would be $\$ 86$ million (difference between total economic impacts on the region with the low and medium traceability cases). The total indirect impacts on industries with the medium traceability are estimated to be $\$ 112$ million. The value added will decrease by $\$ 79$ million, and total household income will be reduced by $\$ 56$ million. State and local government revenue will fall by $\$ 19$ million because of reduced taxes paid by industries and households.

In the case of a high level of traceability (Table 6), the total regional impact is estimated to be $\$ 337$ million $(28 \%$ less than the loss of the low-traceability

\footnotetext{
7 Estimate of economic impact is $\$ 193$ million with the final demand-driven SAM multipliers.
} 
Table 4. Regional Economic Impact of Hypothetical Foot-and-Mouth Disease Outbreaks, Low Traceability

\begin{tabular}{|c|c|c|c|c|c|c|c|}
\hline \multirow{2}{*}{$\frac{\text { Sectors }}{\text { Impact on industries (indirect) }}$} & \multicolumn{2}{|c|}{$\begin{array}{c}\text { Cattle Ranching and } \\
\text { Farming (million dollars) }\end{array}$} & \multicolumn{2}{|c|}{$\begin{array}{l}\text { Other Livestock } \\
\text { (million dollars) }\end{array}$} & \multicolumn{2}{|c|}{$\begin{array}{l}\text { Cattle and Hog Slaughter } \\
\text { (million dollars) }\end{array}$} & \multirow[t]{2}{*}{$\begin{array}{l}\text { Total (million } \\
\text { dollars) }\end{array}$} \\
\hline & Backward $^{\mathrm{a}}$ & Forward $^{\mathrm{b}}$ & Backward & Forward & Backward & Forward & \\
\hline Grain farming & 0.00 & -0.01 & 0.00 & 0.00 & 0.00 & 0.00 & -0.02 \\
\hline Mining & -0.11 & -0.11 & -0.05 & -0.08 & -0.08 & -0.37 & -0.79 \\
\hline Utilities & -1.13 & -0.05 & -0.29 & -0.04 & -1.02 & -0.21 & -2.73 \\
\hline Manufacturing & -3.82 & -21.57 & -1.51 & -5.15 & -1.85 & -4.44 & -38.34 \\
\hline Wholesale trade & -2.46 & -0.18 & -0.59 & -0.15 & -2.17 & -0.78 & -6.34 \\
\hline Retail & -1.92 & -0.31 & -0.56 & -0.26 & -1.66 & -1.30 & -6.00 \\
\hline Transportation and warehousing & -2.10 & -0.22 & -0.67 & -0.15 & -2.82 & -0.70 & -6.66 \\
\hline FIRE $^{\mathrm{c}}$ & -14.24 & -0.99 & -2.80 & -0.86 & -9.18 & -4.61 & -32.68 \\
\hline Other services & -7.69 & -1.29 & -2.15 & -1.11 & -9.22 & -6.72 & -28.18 \\
\hline Government & -3.26 & -0.47 & -0.88 & -0.47 & -2.54 & -2.33 & -9.95 \\
\hline Total impacts on industries & -38.74 & -25.77 & -9.96 & -8.59 & -31.63 & -22.59 & -137.27 \\
\hline
\end{tabular}


Table 4. Continued

\begin{tabular}{|c|c|c|c|c|c|c|c|}
\hline \multirow{2}{*}{$\frac{\text { Sectors }}{\text { Impact on value added (indirect) }}$} & \multicolumn{2}{|c|}{$\begin{array}{c}\text { Cattle Ranching and } \\
\text { Farming (million dollars) }\end{array}$} & \multicolumn{2}{|c|}{$\begin{array}{l}\text { Other Livestock } \\
\text { (million dollars) }\end{array}$} & \multicolumn{2}{|c|}{$\begin{array}{l}\text { Cattle and Hog Slaughter } \\
\text { (million dollars) }\end{array}$} & \multirow[t]{2}{*}{$\begin{array}{l}\text { Total (million } \\
\text { dollars) }\end{array}$} \\
\hline & Backward & Forward & Backward & Forward & Backward & Forward & \\
\hline Employment compensation & -15.15 & -1.71 & -4.76 & -1.82 & -17.04 & -9.09 & -49.57 \\
\hline Proprietary income & -0.25 & -0.18 & 0.79 & -0.19 & -1.42 & -0.90 & -2.15 \\
\hline Other property income & -21.91 & -0.38 & -7.67 & -0.39 & -6.44 & -1.95 & -38.74 \\
\hline Indirect business taxes & -2.88 & -0.21 & -0.79 & -0.15 & -1.65 & -0.91 & -6.59 \\
\hline Impacts on household income (induced) & Backward & Forward & Backward & Forward & Backward & Forward & \\
\hline Low-income household & -2.19 & -0.50 & -0.69 & -0.53 & -1.82 & -2.82 & -8.55 \\
\hline Medium-income household & -11.48 & -1.45 & -3.48 & -1.55 & -10.39 & -7.85 & -36.21 \\
\hline High-income household & -8.37 & -0.77 & -2.19 & -0.81 & -7.01 & -3.79 & -22.94 \\
\hline Total impacts on household & -22.04 & -2.72 & -6.36 & -2.90 & -19.23 & -14.46 & -67.70 \\
\hline State and local government revenue (induced) & $\begin{array}{r}\text { Backward } \\
-8.14 \\
\end{array}$ & $\begin{array}{r}\text { Forward } \\
-1.10 \\
\end{array}$ & $\begin{array}{c}\text { Backward } \\
-2.23\end{array}$ & $\begin{array}{r}\text { Forward } \\
-0.79 \\
\end{array}$ & $\begin{array}{c}\text { Backward } \\
-5.84 \\
\end{array}$ & $\begin{array}{r}\text { Forward } \\
-4.55 \\
\end{array}$ & -22.65 \\
\hline $\begin{array}{l}\text { Indirect and induced regional impact(not } \\
\text { including direct effects) }\end{array}$ & -109.11 & -32.07 & -30.97 & -14.83 & -83.24 & -54.45 & -324.66 \\
\hline $\begin{array}{l}\text { Total regional impact (including direct } \\
\text { impact) }\end{array}$ & & & & & & & -468.39 \\
\hline
\end{tabular}

${ }^{a}$ The backward linkage is “a sector's relationship with upstream sectors (suppliers) that provide goods and services used as intermediate inputs” (Seung and Waters, 2009 , p. 19), which measures the change in output in endogenous sectors attributable to change in the output of exogenized sectors.

${ }^{b}$ Seung and Waters (2009, pp. 19-20) define the forward linkages as "a sector's relationship with its downstream demanders who purchase goods and services from the exogenized sectors."

'Finance, insurance, real estate, and education.

${ }^{\mathrm{d}}$ Direct impact is reported in Table 2. 
Table 5. Regional Economic Impact of Hypothetical Foot-and-Mouth Disease Outbreaks, Medium Traceability

\begin{tabular}{|c|c|c|c|c|c|c|c|}
\hline \multirow{2}{*}{$\frac{\text { Sectors }}{\text { Impact on industries (indirect) }}$} & \multicolumn{2}{|c|}{$\begin{array}{c}\text { Cattle Ranching and } \\
\text { Farming (million dollars) }\end{array}$} & \multicolumn{2}{|c|}{$\begin{array}{l}\text { Other Livestock } \\
\text { (million dollars) }\end{array}$} & \multicolumn{2}{|c|}{$\begin{array}{l}\text { Cattle and Hog Slaughter } \\
\text { (million dollars) }\end{array}$} & \multirow[t]{2}{*}{$\begin{array}{l}\text { Total (million } \\
\text { dollars) }\end{array}$} \\
\hline & Backward $^{\mathrm{a}}$ & Forward $^{\mathrm{b}}$ & Backward & Forward & Backward & Forward & \\
\hline Other ag, forestry, fish, and hunting & -0.67 & -0.07 & -0.06 & -0.04 & -0.03 & -0.05 & -0.91 \\
\hline Grain farming & 0.00 & -0.01 & 0.00 & 0.00 & 0.00 & 0.00 & -0.01 \\
\hline Mining & -0.09 & -0.08 & -0.04 & -0.07 & -0.06 & -0.30 & -0.65 \\
\hline Utilities & -0.88 & -0.04 & -0.26 & -0.04 & -0.84 & -0.17 & -2.23 \\
\hline Construction & -0.90 & -0.39 & -0.36 & -0.24 & -0.89 & -0.89 & -3.66 \\
\hline Manufacturing & -2.98 & -16.81 & -1.36 & -4.66 & -1.53 & -3.68 & -31.02 \\
\hline Wholesale trade & -1.92 & -0.14 & -0.53 & -0.14 & -1.80 & -0.65 & -5.18 \\
\hline Retail & -1.50 & -0.24 & -0.50 & -0.23 & -1.38 & -1.08 & -4.92 \\
\hline Transportation and warehousing & -1.64 & -0.17 & -0.61 & -0.14 & -2.33 & -0.58 & -5.46 \\
\hline FIRE $^{c}$ & -11.10 & -0.77 & -2.53 & -0.78 & -7.59 & -3.82 & -26.59 \\
\hline Other services & -5.99 & -1.00 & -1.95 & -1.00 & -7.63 & -5.56 & -23.14 \\
\hline Government & -2.54 & -0.37 & -0.80 & -0.42 & -2.10 & -1.93 & -8.16 \\
\hline Total impacts on industries & -30.19 & -20.08 & -9.01 & -7.77 & -26.17 & -18.69 & -111.91 \\
\hline
\end{tabular}


Table 5. Continued

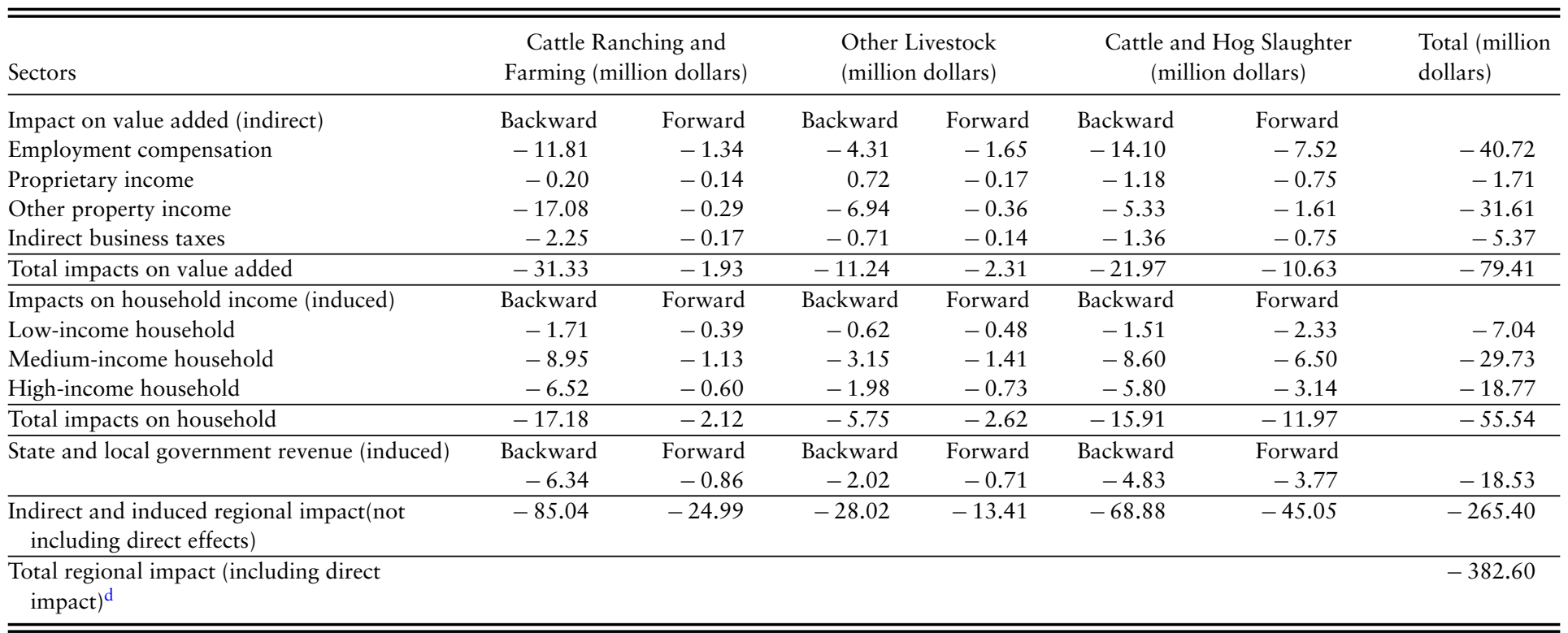

${ }^{a}$ The backward linkage is “a sector's relationship with upstream sectors (suppliers) that provide goods and services used as intermediate inputs” (Seung and Waters, 2009 , p. 19), which measures the change in output in endogenous sectors attributable to change in the output of exogenized sectors.

${ }^{b}$ Seung and Waters (2009, pp. 19-20) define the forward linkages as "a sector's relationship with its downstream demanders who purchase goods and services from the exogenized sectors."

${ }^{c}$ Finance, insurance, real estate, and education.

${ }^{\mathrm{d}}$ Direct impact is reported in Table 2. 
Table 6. Regional Economic Impact of Hypothetical Foot-and-Mouth Disease Outbreaks, High Traceability

\begin{tabular}{|c|c|c|c|c|c|c|c|}
\hline \multirow{2}{*}{$\begin{array}{l}\text { Sectors } \\
\text { Impact on industries (indirect) }\end{array}$} & \multicolumn{2}{|c|}{$\begin{array}{c}\text { Cattle Ranching and } \\
\text { Farming (million dollars) }\end{array}$} & \multicolumn{2}{|c|}{$\begin{array}{l}\text { Other Livestock } \\
\text { (million dollars) }\end{array}$} & \multicolumn{2}{|c|}{$\begin{array}{l}\text { Cattle and Hog Slaughter } \\
\text { (million dollars) }\end{array}$} & \multirow[t]{2}{*}{$\begin{array}{l}\text { Total (million } \\
\text { dollars) }\end{array}$} \\
\hline & Backward $^{\mathrm{a}}$ & Forward $^{\mathrm{b}}$ & Backward & Forward & Backward & Forward & \\
\hline Grain farming & 0.00 & 0.00 & 0.00 & 0.00 & 0.00 & 0.00 & -0.01 \\
\hline Mining & -0.08 & -0.07 & -0.04 & -0.07 & -0.05 & -0.26 & -0.57 \\
\hline Utilities & -0.76 & -0.03 & -0.25 & -0.04 & -0.73 & -0.15 & -1.96 \\
\hline Manufacturing & -2.59 & -14.60 & -1.33 & -4.55 & -1.32 & -3.17 & -27.55 \\
\hline Wholesale trade & -1.66 & -0.12 & -0.52 & -0.14 & -1.55 & -0.56 & -4.55 \\
\hline Retail & -1.30 & -0.21 & -0.49 & -0.23 & -1.19 & -0.93 & -4.34 \\
\hline Transportation and warehousing & -1.42 & -0.15 & -0.59 & -0.14 & -2.01 & -0.50 & -4.80 \\
\hline FIRE $^{c}$ & -9.64 & -0.67 & -2.47 & -0.76 & -6.54 & -3.29 & -23.37 \\
\hline Other services & -5.20 & -0.87 & -1.90 & -0.98 & -6.58 & -4.79 & -20.32 \\
\hline Government & -2.21 & -0.32 & -0.78 & -0.41 & -1.81 & -1.66 & -7.19 \\
\hline Total impacts on industries & -26.23 & -17.44 & -8.79 & -7.58 & -22.56 & -16.11 & -98.70 \\
\hline
\end{tabular}


Table 6. Continued

\begin{tabular}{|c|c|c|c|c|c|c|c|}
\hline \multirow{2}{*}{$\frac{\text { Sectors }}{\text { Impact on value added (indirect) }}$} & \multicolumn{2}{|c|}{$\begin{array}{c}\text { Cattle Ranching and } \\
\text { Farming (million dollars) }\end{array}$} & \multicolumn{2}{|c|}{$\begin{array}{l}\text { Other Livestock } \\
\text { (million dollars) }\end{array}$} & \multicolumn{2}{|c|}{$\begin{array}{l}\text { Cattle and Hog Slaughter } \\
\text { (million dollars) }\end{array}$} & \multirow[t]{2}{*}{$\begin{array}{l}\text { Total (million } \\
\text { dollars) }\end{array}$} \\
\hline & Backward & Forward & Backward & Forward & Backward & Forward & \\
\hline Employment compensation & -10.25 & -1.16 & -4.20 & -1.61 & -12.15 & -6.48 & -35.86 \\
\hline Proprietary income & -0.17 & -0.12 & 0.70 & -0.17 & -1.01 & -0.64 & -1.41 \\
\hline Other property income & -14.83 & -0.26 & -6.77 & -0.35 & -4.59 & -1.39 & -28.19 \\
\hline Indirect business taxes & -1.95 & -0.14 & -0.69 & -0.14 & -1.17 & -0.65 & -4.74 \\
\hline Impacts on household income (induced) & Backward & Forward & Backward & Forward & Backward & Forward & \\
\hline Low-income household & -1.48 & -0.34 & -0.60 & -0.47 & -1.30 & -2.01 & -6.21 \\
\hline Medium-income household & -7.77 & -0.98 & -3.07 & -1.37 & -7.41 & -5.60 & -26.21 \\
\hline High-income household & -5.67 & -0.52 & -1.93 & -0.71 & -5.00 & -2.71 & -16.54 \\
\hline Total impacts on household & -14.92 & -1.84 & -5.61 & -2.55 & -13.71 & -10.31 & -48.95 \\
\hline State and local government revenue (induced) & $\begin{array}{c}\text { Backward } \\
-5.51 \\
\end{array}$ & $\begin{array}{r}\text { Forward } \\
-0.75 \\
\end{array}$ & $\begin{array}{c}\text { Backward } \\
-1.97\end{array}$ & $\begin{array}{r}\text { Forward } \\
-0.70\end{array}$ & $\begin{array}{c}\text { Backward } \\
-4.17 \\
\end{array}$ & $\begin{array}{r}\text { Forward } \\
-3.25 \\
\end{array}$ & -16.33 \\
\hline $\begin{array}{l}\text { Indirect and induced regional impact (not } \\
\text { including direct effects) }\end{array}$ & -73.86 & -21.71 & -27.33 & -13.08 & -59.36 & -38.83 & -234.17 \\
\hline $\begin{array}{l}\text { Total regional impact (including direct } \\
\text { impact) }\end{array}$ & & & & & & & -337.28 \\
\hline
\end{tabular}

${ }^{a}$ The backward linkage is “a sector's relationship with upstream sectors (suppliers) that provide goods and services used as intermediate inputs” (Seung and Waters, 2009 , p. 19), which measures the change in output in endogenous sectors attributable to change in the output of exogenized sectors.

${ }^{b}$ Seung and Waters (2009, pp. 19-20) define the forward linkages as "a sector's relationship with its downstream demanders who purchase goods and services from the exogenized sectors."

${ }^{c}$ Finance, insurance, real estate, and education.

${ }^{\mathrm{d}}$ Direct impact is reported in Table 2. 
case). ${ }^{8}$ The gain of implementing a high level of traceability would be $\$ 131$ million in comparison with having a low level of traceability. The total indirect impacts on industries when a high level of traceability is available during an FMD outbreak are estimated to be $\$ 99$ million in Utah. The value added will decrease by $\$ 70$ million, and total household income will be reduced by $\$ 49$ million. State and local government revenue will fall by $\$ 16$ million.

The results suggest substantial benefits arising from a high level of traceability in the case of an FMD outbreak, but do the benefits justify the costs associated with traceability? A Congressional Research Service (CRS) report by Greene (2010) notes that a traceability (animal identification) system requiring $100 \%$ participation would have a total cost of between $\$ 5$ and $\$ 6$ per head for cattle, $\$ 0.06$ per head for swine, and between $\$ 1.07$ and $\$ 1.39$ per head for sheep (Greene, 2010, table 5, pp. 22-23). Obviously, the costs of animal identification and traceability are very unequal given much higher costs for cattle than for swine on a per head basis. The CRS report (Greene, 2010) indicates that the unevenness of costs (borne principally by the cattle industry) was a major reason for the lack of political support for NAIS. Swine and poultry have much lower costs per head for animal identification and tracking because identification for these species in NAIS was on a group or a "lot" basis, whereas other species such as cattle and sheep that are not typically together in groups for their entire lives would have been required to have individual animals identified and tracked.

The average annual total cattle inventory in Utah between 2010 and 2015 inclusive was about 805,000 head. This suggests a total cost for NAIS in Utah of about $\$ 4.48$ million $(805,000$ head $\times \$ 5.50 /$ head). When one compares the potential benefits and costs, it becomes apparent that the cost of implementing traceability systems is likely not the primary impediment to their implementation. Other concerns such as loss of privacy, unequal sharing of costs, and the potential for retailers to shift costs upstream may likely be more pertinent reasons for the overall failure of NAIS to be implemented. These concerns are primarily political suggesting that a major event, such as an FMD outbreak, may eventually be what drives the implementation of animal identification and traceability in the United States

\section{Summary and Concluding Remarks}

This study reports the findings for an analysis using an SDSAM model to examine the impact of a hypothetical FMD outbreak in a relatively isolated part of the United States, Utah, under different levels of livestock traceability. The analysis demonstrates that significant regional economic impact would result from an FMD outbreak but that improved levels of traceability would be beneficial in helping to reduce the negative economic consequences of the outbreak.

8 Estimate of economic impact is $\$ 169$ million with the (final) demand-driven SAM multipliers. 
The hypothetical FMD outbreak and the resulting direct impacts are estimated using the NAADSM, which is the stochastic, spatial, and state-transition simulation model. The scenario for a low level of trace success (the current state of animal identification) estimated an FMD outbreak would result in 36.6\% of Utah's fed cattle population needing to be depopulated. This percentage is reduced to $31.4 \%$ under a medium level of trace success (reflective of the significantly adopted traceability system, but one that might not be fully operational), and $27.7 \%$ under the highest level of traceability considered (reflective of the nationally adopted, agile, and accurate system of traceability). In the case of hogs under the lowest level of trace success, $13.7 \%$ of slaughter hogs are depopulated. Under the medium and high levels of traceability, $12.2 \%$ and $12.1 \%$ of slaughter hogs are depopulated, respectively. This reflects the indirect benefits of higher levels of cattle traceability, which limits the indirect spread of the disease to other animal species through accelerating the response to an FMD outbreak in the cattle industry.

The regional impacts of various outbreak scenarios are computed with the backward and forward SDSAM multipliers using the direct impacts of FMD outbreaks and are reported in Tables 4, 5, and 6. In the case of a low level of traceability, total regional impact (direct + indirect + induced) is estimated to be $\$ 468$ million. In the case of a medium level of traceability, the total regional impact is $\$ 383$ million (18\% less than the loss estimated for a low level of traceability). In the case of a high level of traceability, the regional economic impact is estimated to be $\$ 337$ million ( $28 \%$ less than the loss estimated for the low level of traceability). Clearly, a high level of traceability is beneficial because the gain of having the $90 \%$ level of traceability would be $\$ 86$ million compared with the medium level $(60 \%)$ of traceability and $\$ 131$ million compared with the lowest level of traceability (30\%).

Results in this research indicate two relevant policy implications. First, if an FMD outbreak occurs, economic losses would be substantial to the local economy, which is in line with Pendell et al. (2007). Second, facilitating animal traceability would be an important tool to reduce the economic loss. For example, the economic gain in an FMD outbreak of having a well-functioning traceability system $(90 \%)$ compared with the current system for traceability $(30 \%)$ would be $\$ 131$ million even in an isolated market such as Utah. The gain would be much higher in other regions such as in the Midwest where much larger feedlots are operating than in Utah. Because cost for better traceability accrues to the individual firm, incentivizing adoption of better traceability is necessary.

The decision of whether to implement animal identification and traceability in Utah and the United States is primarily a political issue. However, because such large economic benefits would accrue to animal traceability systems as a result of their ability to limit economic losses in time of disease or other breakdowns of the livestock system, policy makers should continue to support improved technologies of animal and meat traceability. These may be undertaken 
more efficiently and at less cost than systems offered by current technology. Precisely what the components or technologies comprising these future systems may look like is not known, but due diligence suggests that it is important to continue to consider how these systems could best be implemented. In the case of Utah, these baseline numbers regarding potential economic losses affecting its main agricultural industry may assist supporters of the measure, including policy makers and lawmakers, with discussion regarding such a policy.

In addition, there would be a large economic impact from international trade restriction because of the Utah FMD outbreak. Economic loss from the trade restriction may be estimated by assuming the same period of recovery that affected international trade from a past BSE event. However, this article aims to investigate regional economic impact from Utah livestock depopulation because of FMD, and thus the loss from an international trade ban is not included in the analysis. The potential economic gain of the traceability would be larger if the economic loss from the trade were added.

Unfortunately, limiting the impact to Utah is a major limitation in the study. First, as noted, FMD would very likely not be limited to Utah. Second, restricting the study to a small geographic area might be relatively unreasonable because the traceability would be implemented over a much wider region.

\section{References}

Bailey, D. "Political Economy of the U.S. Cattle and Beef Industry: Innovation Adoption and Implications for the Future." Journal of Agricultural and Resource Economics 32,3(2007):403-16.

Bailey, D., and J. Slade. "Factors Influencing Support for a National Animal Identification System for Cattle in the United States.” Economic Research Institute Study Papers, 283, Logan: Department of Economics, Utah State University, 2004.

Brester, G., K. Dhuyvetter, D. Pendell, T. Schroeder, and G. Tonsor. Economic Assessment of Evolving Red Meat Export Market Access Requirements for Traceability of Livestock and Meat. Manhattan: Department of Agricultural Economics, Kansas State University, Project Report submitted to the U. S. Meat Export Federation, March 2011. Internet site: http://www.agmanager.info/livestock/marketing/AnimalID/ USMEF-Final-Project-Report-Tonsor_03-30-11.pdf (Accessed March 12, 2015).

Cozzens, T., K. Gebhardt, S. Shwiff, M. Lutman, and K. Pedersen. "Modeling the Economic Impact of Feral Swine-Transmitted Foot-and-Mouth Disease: A Case Study from Missouri.” U.S. Department of Agriculture (USDA) National Wildlife Research Center - Staff Publications, Paper 1262, Fort Collins, CO: USDA, Animal and Plant Health Inspection Service, 2010. Internet site: http://digitalcommons.unl.edu/icwdm_usdanwrc/ 1262 (Accessed May 27, 2015).

Dickinson, D.L., and D. Bailey. "Experimental Evidence on Willingness to Pay for Red Meat Traceability in the United States, Canada, the United Kingdom, and Japan." Journal of Agricultural and Applied Economics 37,3(2005):537-48.

- "Meat Traceability: Are U.S. Consumers Willing to Pay for It?" Journal of Agricultural and Resource Economics 27,2(2002):348-64. 
Ekboir, J.M. Potential Impact of Foot-and-Mouth Disease in California: The Role and Contribution of Animal Health Surveillance and Monitoring Services. Davis: Agricultural Issues Center, University of California, Davis. 1999.

Fernández-Macho, J., C. Gallastegui, and P. González. "Economic Impacts of TAC Regulation: A Supply-Driven SAM Approach.” Fisheries Research 9,1-3(2008): 225-34.

Garner, M.G., and M.B. Lack. "An Evaluation of Alternative Control Strategies for Foot-andMouth Disease in Australia: A Regional Approach.” Preventive Veterinary Medicine 23,1-2(1995):9-32.

Ghosh, A. "Input-Output Approach to an Allocative System.” Economica 25,1(1958):58-64.

Greene, J.L. Animal Identification and Traceability: Overview and Issues. Washington, DC: Congressional Research Service (CRS), CRS Report for Congress R40832, November 2010.

Harvey, N., A. Reeves, M.A. Schoenbaum, F.J. Zagmutt-Vergara, C. Dube, A.E. Hill, B.A. Corso, W.B. McNab, C.I. Cartwright, and M.D. Salman. "The North American Animal Disease Spread Model: A Simulation Model to Assist Decision Making in Evaluating Animal Disease Incursions.” Preventive Veterinary Medicine 82,34(2007):176-97.

Hill, A., and A. Reeves. User's Guide for the North American Animal Disease Spread Model 3.0.2nd ed. Fort Collins: Animal Population Health Institute, Colorado State University, 2006.

Hobbs, J.E., D. Bailey, D.L. Dickinson, and M. Haghiri. "Traceability in the Canadian Red Meat Sector: Do Consumers Care?" Canadian Journal of Agricultural Economics 53,1(2005):47-65.

Holland, D., and P. Wyeth. SAM Multipliers: Their Decomposition, Interpretation, and Relationship to Input-Output Multipliers. Pullman: College of Agricultural and Home Economics Research Center, Washington State University, Research Bulletin XB 1027, 1993.

Jones, J. "Effects of a Traceability System on the Economic Impact of a Foot-and-Mouth Disease Outbreak.” Master's thesis, Department of Agribusiness and Agricultural Economics, University of Manitoba, Winnipeg, MB, Canada, 2010.

Jordan, K. Testimony of Karen Jordan, DVM, National Milk Producers Federation, before the U.S. House of Representatives Committee on Agriculture Subcommittee on Livestock, Dairy, and Poultry Hearing on Animal Identification, March 11, 2009. 2009. Internet site: http://nmpf.org/files/file/Jordan\%20Testimony\%203-11-09.pdf (Accessed March 12, 2015).

Kim, M.-K. "Supply Driven Input-Output Analysis: Case of 2010-2011 Foot-and-Mouth Disease in Korea." Journal of Rural Development 38,2(2015):173-88.

Klobuchar, A. The Economic Contribution of America's Farmers and the Importance of Agricultural Exports. Washington, DC: Joint Economic Committee, U.S. Congress, September 2013. Internet site: http://www.jec.senate.gov/public/?a=Files.Serve\&File_ $\mathrm{id}=266 \mathrm{a} 0 \mathrm{bf3}-5142-4545-\mathrm{b} 806-\mathrm{ef9fd78b9c2f}$ (Accessed March 12, 2015).

Lawrence, J.D. National Animal Identification: Background and Basics for Cattle Producers. Ames: Iowa Beef Center, Iowa State University, PM 1962, August 2004. Internet site: http://www.extension.umn.edu/agriculture/beef/components/docs/ national-animal-identification.pdf (Accessed March 13, 2015).

Leontief, W. The Structure of the American Economy. Cambridge, MA: Harvard University Press, 1941. 
Leung, P., and S. Pooley. "Regional Economic Impacts of Reductions in Fisheries Production: A Supply-Driven Approach.” Marine Resource Economics 16,4(2001): 251-62.

Liddell, S., and D. Bailey. "Market Opportunities and Threats to the U.S. Pork Industry Posed by Traceability Systems." International Food and Agribusiness Management Review 4,3(2001):287-302.

Lind, M. "Dairy Industry Approaches Goal in Traceability Compliance." FoodOnline. July 8, 2014. Internet site: https://www.foodonline.com/doc/dairy-industryapproaches-goal-in-traceability-compliance-0001 (Accessed March 29, 2017).

Korea Rural Economic Institute (KREI). “2010 2011 Foot-and-Mouth Disease.” White paper, Seoul: KREI, 2011.

Mahul, O., and B. Durand. "Simulated Economic Consequences of Foot-and-Mouth Disease Epidemics and Their Public Control in France." Preventive Veterinary Medicine 47,12(2000):23-38.

Mahul, O., and A. Gohin. "Irreversible Decision Making in Contagious Animal Disease Control under Uncertainty: An Illustration Using FMD in Brittany.” European Review of Agricultural Economics 26,1(1999):39-58.

Mardones, F., A. Perez, J. Sanchez, M. Alkhamis, and T. Carpenter. "Parameterization of the Duration of Infection Stages of Serotype O Foot-and-Mouth Disease and Meta-analysis with Application to Simulation Models.” Veterinary Research 41,4(2010):1-15.

McReynolds, S.W. "Modeling Management of Foot-and-Mouth Disease in the Central United States.” Ph.D. dissertation, Department of Diagnostic Medicine and Pathobiology, College of Veterinary Medicine, Kansas State University, Manhattan, 2013.

MIG Inc. IMPLAN System (data and software). Stillwater, MN: MIG Inc. Internet site: http: //www.implan.com (Accessed March 29, 2017).

Moon, S.H., W.S. Park, and S.Y. Soh. "Economical Ripple Effects of the Foot-and-Mouth on the Korean Economy Using Input-Output Analysis.” Korean Journal of Agricultural Management and Policy 40,3(2013):511-31.

Morell, S.F. "Update on the National Animal Identification System (NAIS)." Weston A. Price Foundation. April 10, 2006. Internet site: http://www.westonaprice.org/action-alerts/ update-on-the-national-animal-identification-system-nais/ (Accessed March 12, 2015).

National Pork Producers Council (NPPC). "NPPC Urges Congress to Back Animal ID System.” Washington, DC: NPPC, 2009. Internet site: http://nppc.org/ nppc-urges-congress-to-back-animal-id-system/ (Accessed March 12, 2015).

Paarlberg, P.L., A.H. Seitzinger, J.G. Lee, and K.H. Mathews, Jr. Economic Impacts of Foreign Animal Disease. Washington, DC: U.S. Department of Agriculture, Economic Research Service, Economic Research Report No. 57, May 2008.

Park, M., Y.H. Jin, and D.A. Bessler. "The Impacts of Animal Disease Crises on the Korean Meat Market.” Agricultural Economics 39,2(2008):183-95.

Pendell, D.L. "Value of Animal Traceability System in Managing a Foot-and-Mouth Disease Outbreak in Southwest Kansas." PhD dissertation, Department of Agricultural Economics, Kansas State University, Manhattan, 2006.

Pendell, D.L., J. Leatherman, T.C. Schroeder, and G.S. Alward. "The Economic Impacts of a Foot-and-Mouth Disease Outbreak: A Regional Analysis." Journal of Agricultural and Applied Economics 39,1(2007):19-33.

Pendell, D.L., T.L. Marsh, K.H. Coble, J.L. Lust, and S.C. Szmania. "Economic Assessment of FMDv Releases from the National Bio and Agro Defense Facility." PLoS ONE 10,6(2015):e0129134. doi:10.1371/journal.pone.0129134. 
Polo, C., and E. Valle. "Input-Output and SAM models." Handbook of Research Methods in Tourism: Quantitative and Qualitative Approaches. L. Dwyer, A. Gill, and N. Seetaram, eds. Cheltenham, UK: Edward Elgar, 2012, pp. 227-60.

Premashthira, S., M.D. Salman, A.E. Hill, R.M. Reich, and B.A. Wagner. "Epidemiological Simulation Modeling and Spatial Analysis for Foot-and-Mouth Disease Control Strategies: A Comprehensive Review.” Animal Health Research Reviews 12,2(2011):225-34.

Reeves, A., R. Hupalo, K.A. Patyk, and A.E. Hill. User's Guide for the North American Animal Disease Spread Model 4.0. Fort Collins: Colorado State University, 2012. Internet site: http://www.naadsm.org/naadsm/files/documentation/NAADSMUsersGuide-4_ 0.pdf (Accessed February 10, 2017).

Rich, K.M., G.Y. Miller, and A. Winter-Nelson. “A Review of Economic Tools for Assessment of Animal Disease Outbreaks." Revue Scientifique et Technique de l'Office International des Epizooties 24,3(2005):833-45.

Schroeder, T.C., D.L. Pendell, M.W. Sanderson, and S. McReynolds. "Economic Impact of Alternative FMD Emergency Vaccination Strategies in the Midwestern United States." Journal of Agricultural and Applied Economics 47,1(2015):47-76.

Schroeder, T.C., and G.T. Tonsor. "International Cattle ID and Traceability: Competitive Implications for the US." Food Policy 37,1(2012):31-40.

Scudamore, J.M. "Origin of the UK Foot and Mouth Disease Epidemic in 2001." London: Department for Environment, Food and Rural Affairs, June 2002. Internet site: http://www.ecolab.com/expertise-and-innovation/microbial-risks/ /media/ 229e1f86251e474da055612d15af4b8e.ashx (Accessed May 27, 2015).

Seung, C.-K., and E.C. Waters. "Measuring the Economic Linkage of Alaska Fisheries: A Supply-Driven Social Accounting Matrix (SDSAM) Approach.” Fisheries Research 97,1-2(2009):17-23.

Thompson, D., P. Muriel, D. Russell, P. Osborne, A. Bromley, M. Rowland, S. Creigh-Tyte, and C. Brown. "Economic Costs of the Foot and Mouth Disease Outbreak in the United Kingdom in 2001." Revue Scientifique et Technique de l'Office International des Epizooties 21,3(2002):675-87.

Ukkestad, C.M. The Benefits of Animal Traceability Systems on a Foot-and-Mouth Disease Outbreak in Utah. Master's thesis, Department of Applied Economics, Utah State University, Logan, 2014.

U.S. Department of Agriculture (USDA). National Animal Identification System (NAIS) (Draft). Washington, DC: USDA, November 2006. Internet site: http://www.aphis.usda. gov/traceability/downloads/NAIS-UserGuide.pdf (Accessed March 12, 2015).

U.S. Department of Agriculture, Animal and Plant Health Inspection Service. "Traceability for Livestock Moving Interstate.” Federal Register 78,6(2013):2040-75.

U.S. Department of Agriculture, Economic Research Service. "Cattle \& Beef." December 2014. Internet site: http://www.ers.usda.gov/topics/animal-products/cattle-beef/ statistics-information.aspx (Accessed March 13, 2015).

U.S. Department of Agriculture, National Agricultural Statistics Service (USDA-NASS), Utah Field Office. Utah Agricultural Statistics and Utah Department of Agriculture and Food 2015 Annual Report. Salt Lake City, UT: USDA-NASS, Utah Field Office, 2015. Internet site: https://www.nass.usda.gov/Statistics_by_State/Utah/Publications/Annual_ Statistical_Bulletin/Pdf/ab15/2015\%20Agricultural\%20Statistics.pdf (Accessed February 2010,2017$)$. 
Ward, R.A., D. Bailey, and R. Jensen. "An American BSE Crisis: Has It Affected the Value of Traceability and Country-of-Origin Certifications for U.S. and Canadian Beef?” International Food and Agribusiness Management Review 8,2(2005):92-114.

Watson, P., J. Wilson, D. Thilmany, and S. Winter. "Determining Economic Contributions and Impacts: What Is the Difference and Why Do We Care?" Journal of Regional Analysis \& Policy 37,2(2007):1-15.

Weston A. Price Foundation. "USDA's Final Rule on Animal ID.” Farm-to-Consumer Legal Defense Fund. January 18, 2013. Internet site: http://www.farmtoconsumer.org/news_ $\mathrm{wp} / \mathrm{p}=3862$ (Accessed March 12, 2015). 